\title{
Benzoxacystol, a benzoxazine-type enzyme inhibitor from the deep-sea strain Streptomyces sp. NTK 935
}

\author{
Jonny Nachtigall ${ }^{1}$, Kathrin Schneider ${ }^{1}$, Christina Bruntner ${ }^{2}$, Alan T Bull ${ }^{3}$, Michael Goodfellow ${ }^{4}$, \\ Heidi Zinecker ${ }^{5}$, , Johannes F Imhoff ${ }^{5}$, Graeme Nicholson ${ }^{6}$, Elisabeth Irran $^{1}$, Roderich D Süssmuth ${ }^{1}$ \\ and Hans-Peter Fiedler ${ }^{2}$
}

Benzoxacystol, a new 1,4-benzoxazine-type metabolite, was produced by strain NTK 935, a marine member of the Streptomyces griseus 16S rRNA clade, isolated from deep-sea sediment collected from the Canary Basin. The structure of benzoxacystol was determined by mass spectrometry, NMR experiments and X-ray analysis. The compound showed an inhibitory activity against the enzyme glycogen synthase kinase $3 \beta$ and a weak antiproliferative activity against mouse fibroblast cells.

The Journal of Antibiotics (2011) 64, 453-457; doi:10.1038/ja.2011.26; published online 20 April 2011

Keywords: 1,4-benzoxazin-3-one; glycogen synthase kinase 3ß; marine Streptomyces

\section{INTRODUCTION}

Actinomycetes from marine sediments collected at various sites in the Atlantic and Pacific Oceans were screened by HPLC-diode array analysis for the production of novel secondary metabolites. Strain NTK 935 was isolated from the same deep-sea sediment core as Streptomyces sp. NTK 937, which we reported recently to produce caboxamycin, a novel antibiotic with a benzoxazole scaffold. ${ }^{2}$ Extracts of strain NTK 935 contained a metabolite having an unusual UV-vis spectrum, which was not identified by means of our in-house developed HPLC database. ${ }^{3}$ HPLC-ESI-MS analysis revealed a molecular mass of 380 , which was- together with UV-vis data-not in accordance with other natural products available in the DNP database. ${ }^{4}$ Therefore, strain NTK 935 was selected for fermentation studies, isolation and characterization of the unusual metabolite; this resulted in the identification of the novel 1,4-benzoxazine structure shown in Figure 1.

This study describes the taxonomy of the producing strain, fermentation and isolation, structural elucidation and biological activity of the new benzoxazine-type metabolite, which was named benzoxacystol.

\section{RESULTS}

Taxonomy and phylogenetic analysis of the producing strain Strain NTK 935 contained LL-diaminopimelic acid in the peptidoglycan, hydrogenated menaquinones with nine isoprene units, and produced straight spore chains of yellowish color on the white aerial mycelium, properties typical of members of the genus Streptomyces. ${ }^{5}$

The phylogenetic analysis of the almost complete 16S rRNA gene sequence revealed that strain NTK 935 was closely related to the type strains of a group of several Streptomyces species sharing similarities with them of approximately $100 \%$ (Figure 2). Members of this group are S. mediolani NBRC $15427 \mathrm{~T}$ (100\% similarity), S. rubiginosohelvus NBRC $12912 \mathrm{~T}$ (100\%), S. griseoplanus AS 4.1868T (99.9\%), S. tanashiensis IFO 12919T (99.9\%), S. globisporus NRRL B-2872T (99.9\%) and S. griseus subsp. griseus NBRC 15744T (99.8\%). The phylogenetic data clearly shows that strain NTK 935 is a member of the $16 \mathrm{~S}$ rRNA S. griseus clade. ${ }^{6}$ Quite interestingly, a strain of S. globisporus was shown to produce a 1,4-benzoxazine-type compound similar to that of strain NTK $935.7,8$

\section{Screening, fermentation and isolation}

Compound 1 was produced by strain NTK 935 in shake-flask cultures in various complex media as monitored by HPLC-diode array analysis. The compound represented a dominant peak in the extracted culture filtrates at a retention time of $7.4 \mathrm{~min}$ (Figure 3). HPLC-ESI-MS analysis revealed a molecular mass of $381.1[\mathrm{M}+\mathrm{H}]^{+}$ in the ESI positive mode for compound 1. Fermentation studies resulted in a maximal biomass at $48 \mathrm{~h}$, whereas production of 1 reached a maximal yield of $14 \mathrm{mgl}^{-1}$ at $72 \mathrm{~h}$, when mannitol and phosphate were depleted in the medium.

\footnotetext{
${ }^{1}$ Institut für Chemie, Technische Universität Berlin, Berlin, Germany; ${ }^{2}$ Mikrobiologisches Institut, Universität Tübingen, Tübingen, Germany; ${ }^{3}$ Research School of Biosciences, University of Kent, Canterbury, UK; ${ }^{4}$ School of Biology, Newcastle University, Newcastle upon Tyne, UK; ${ }^{5}$ Kieler Wirkstoff-Zentrum am Leibniz-Institut für Meereswissenschaften, IFM-GEOMAR, Kiel, Germany and ${ }^{6}$ Institut für Organische Chemie, Universität Tübingen, Tübingen, Germany

${ }^{7}$ Current address: Universität Bonn, Pharmazeutisches Institut, Pharmazeutische Chemie I, 53121 Bonn, Germany.

Correspondence: Professor Dr RD Süssmuth, Institut für Chemie, Technische Universität Berlin, Straße des 17. Juni 124, 10623 Berlin, Germany.

E-mail: suessmuth@chem.tu-berlin.de or Professor Dr H-P Fiedler, Mikrobiologisches Institut, Universität Tübingen, Auf der Morgenstelle 28, 72076 Tübingen, Germany.

E-mail: hans-peter.fiedler@uni-tuebingen.de

Art. no. 59 in 'Biosynthetic Capacities of Actinomycetes'. Art. no. 58: see ref.1.

Received 19 November 2010; revised 15 February 2011; accepted 17 February 2011; published online 20 April 2011
} 
Compound 1 was isolated from the culture filtrate of a 10-1 fermentation by Amberlite XAD-16 (Rohm and Haas, Frankfurt, Germany) column chromatography, followed by ethyl acetate extraction. The raw product was purified by subsequent chromatography steps on diol-modified silica gel, Sephadex LH-20 and Toyopearl HW-40S columns. Compund 1 was obtained in an amount of $25.2 \mathrm{mg}$ as a yellowish powder after concentration to dryness.

\section{Structure determination}

The mass spectrum derived from the HPLC-ESI-MS chromatogram for 1 showed a molecular mass of $381.1[\mathrm{M}+\mathrm{H}]^{+}$. The exact molecular mass was measured by HPLC-ESI-Orbitrap-FT-MS in negative ion<smiles>C=C1Oc2cc(OC)cc(C(=O)SC[C@H](NC(C)=O)C(=O)O)c2NC1=O</smiles>

Figure 1 Structure of benzoxacystol (1). mode as $379.05965 \mathrm{Da}$, which corresponds to the molecular formula $\mathrm{C}_{16} \mathrm{H}_{15} \mathrm{~N}_{2} \mathrm{O}_{7} \mathrm{~S}\left([\mathrm{M}-\mathrm{H}]^{-}{ }_{\text {theor }}=379.06004 \mathrm{Da}, \Delta \mathrm{m}=1.029\right.$ p.p.m. $)$. The physico-chemical properties of $\mathbf{1}$ are given in Table 1.

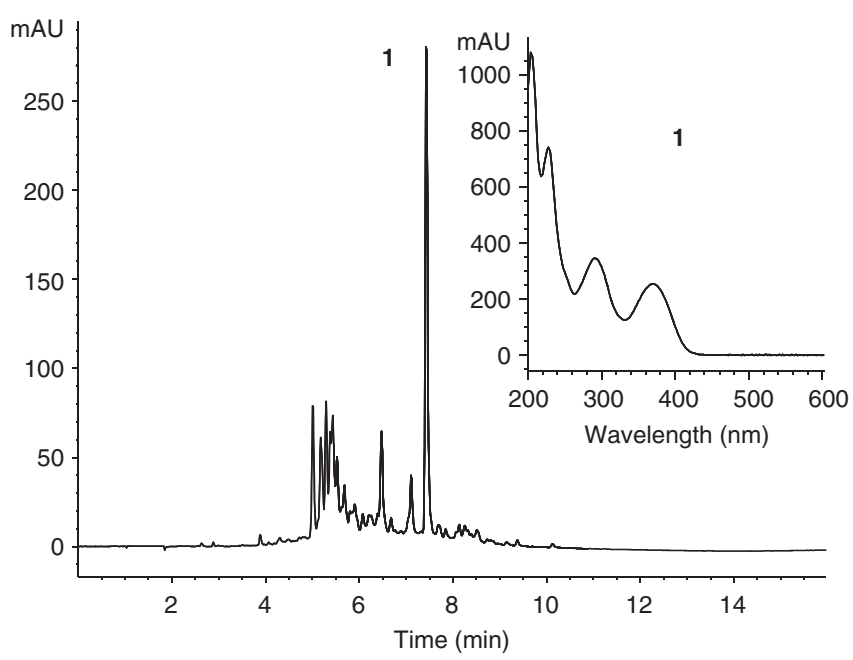

Figure $3 \mathrm{HPLC}$ analysis of a culture filtrate extract from Streptomyces sp. NTK 935 at a fermentation time of $72 \mathrm{~h}$, monitored at $280 \mathrm{~nm}$; insert: UV-vis spectrum of 1 .

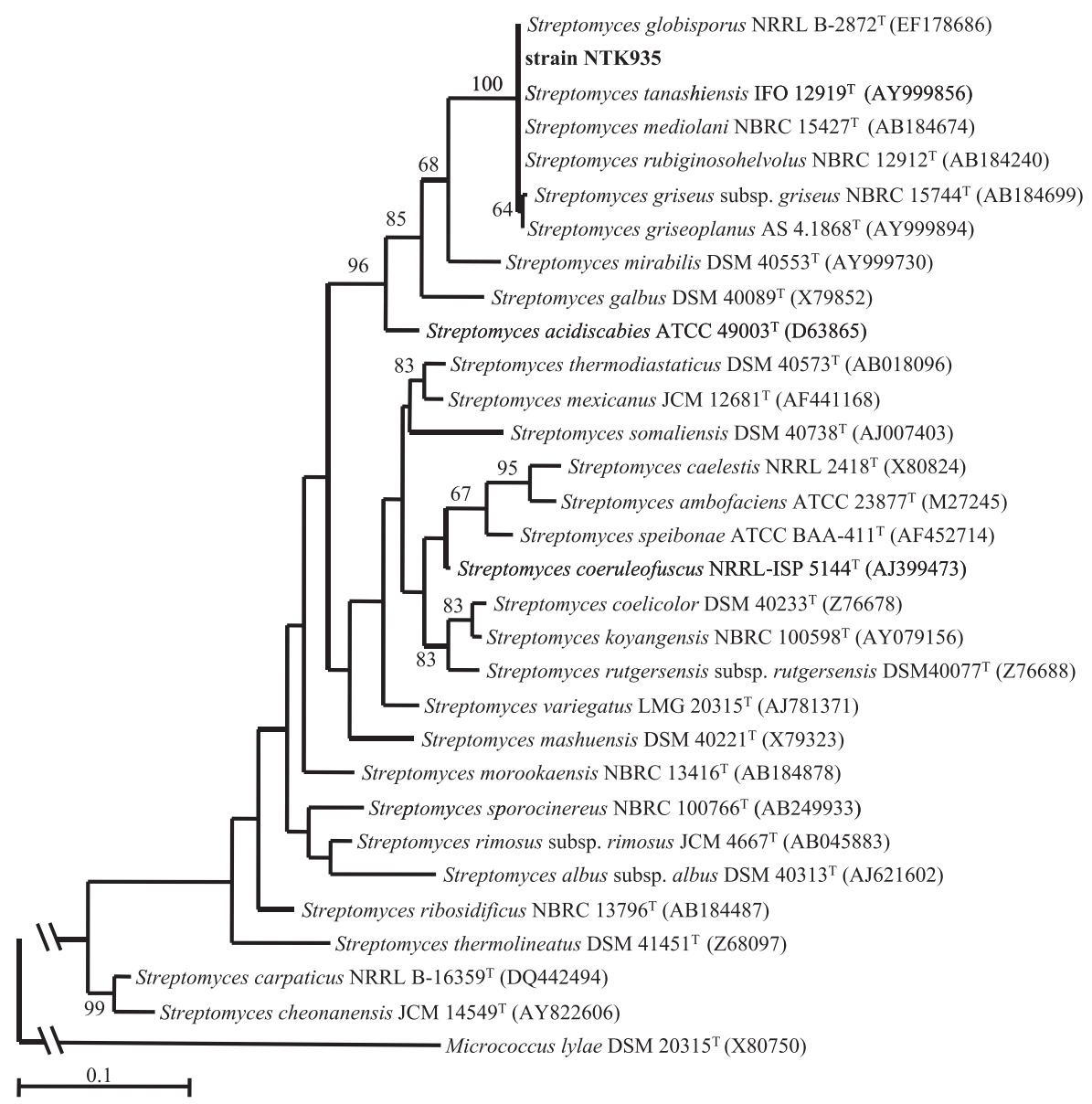

Figure 2 Phylogenetic tree of Streptomyces sp. strain NTK 935, including representatives of the most closely-related type strains and additional members of the genus Streptomyces. Bootstrap values are given in percentage (only numbers above $50 \%$ are shown). 
Table 1 Physico-chemical properties of benzoxacystol (1)

\begin{tabular}{lc}
\hline & 1 \\
\hline Appearance & Yellow powder \\
$H R$-ESI-MS $(\mathrm{m} / z)$ & \\
Measured & $379.05965[\mathrm{M}-\mathrm{H}]^{-}$ \\
Calculated & 379.06004 \\
Molecular formula & $\mathrm{C}_{16} \mathrm{H}_{16} \mathrm{~N}_{2} \mathrm{O}_{7} \mathrm{~S}$ \\
UV $\lambda_{\max }^{\text {MeOH }}(\mathrm{nm})\left(\varepsilon\left(\mathrm{cm}^{2} \mu \mathrm{mol}^{-1}\right)\right)$ & $206(3.26), 226(3.18)$, \\
& $291(2.54), 368(2.16)$ \\
\hline
\end{tabular}

Table $2{ }^{1} \mathrm{H}$ - and ${ }^{13} \mathrm{C}$-NMR spectroscopic data of benzoxacystol (1) in dimethyl sulfoxide- $d_{6}$

\begin{tabular}{|c|c|c|}
\hline Position & $\delta_{H}$ (p.p.m.), (J in Hz) & $\delta_{C}$ (p.p.m.), mult. \\
\hline 1 & - & 154.6, qC \\
\hline 2 & - & 147.2, qC \\
\hline $2 a$ & - & 142.1, qC \\
\hline 3 & $7.05, \mathrm{~s}$ & $106.8, \mathrm{CH}$ \\
\hline 4 & - & 154.3, qC \\
\hline 5 & $7.06, \mathrm{~s}$ & $107.4, \mathrm{CH}$ \\
\hline 6 & - & 121.2, qC \\
\hline $6 a$ & - & 117.9, qC \\
\hline 7 & $10.1, \mathrm{~s}$ & - \\
\hline 8 & $5.47, \mathrm{~d},(1.45), 5.13, \mathrm{~d},(1.43)$ & $98.7, \mathrm{CH}_{2}$ \\
\hline 9 & $3.78, \mathrm{~s}$ & $55.8, \mathrm{CH}_{3}$ \\
\hline 10 & - & 192.1, qC \\
\hline $1^{\prime}$ & $3.57, \mathrm{dd},(8.01,13.3), 3.26, \mathrm{dd},(8.01,13.2)$ & $30.4, \mathrm{CH}_{2}$ \\
\hline $2^{\prime}$ & $4.50, \mathrm{~d},(8.01)$ & $51.0, \mathrm{CH}$ \\
\hline $3^{\prime}$ & - & 171.4, qC \\
\hline $4^{\prime}$ & $8.35, \mathrm{sbr}$ & - \\
\hline $5^{\prime}$ & - & 169.4, qC \\
\hline $6^{\prime}$ & $1.85, \mathrm{~s}$ & $22.1, \mathrm{CH}_{3}$ \\
\hline
\end{tabular}

The ${ }^{1} \mathrm{H}-\mathrm{NMR}$ spectrum of $\mathbf{1}$ showed six signals in the aromatic/ olefinic region and five further signals in the aliphatic region. Integration of the signals revealed 15 protons, with the signals at $\delta_{\mathrm{H}}$ 1.95 p.p.m. and $\delta_{\mathrm{H}} 3.78$ p.p.m., corresponding to one methyl and one methoxy group, respectively. The ${ }^{13} \mathrm{C}-\mathrm{NMR}$ and DEPT spectrum showed one methyl, one methoxy, one aliphatic and one olefinic methylene, two aromatic and one aliphatic methine and nine quaternary carbon atoms. Detailed inspection of the 2D-NMR data (COSY, HSQC and HMBC; Table 2) allowed assignment of the structure of 1 (Figure 1). The ${ }^{1} \mathrm{H}-{ }^{1} \mathrm{H}-\mathrm{COSY}$ spectrum only showed the connection between $\mathrm{H}-1^{\prime}, \mathrm{H}-2^{\prime}$ and $\mathrm{H}-4^{\prime}$, suggesting the presence of a cysteine or serine residue in the structure. The $\mathrm{HMBC}$ correlations from $\mathrm{H}-8$ to $\mathrm{C}-1$ and $\mathrm{C}-2$, from $\mathrm{H}-3$ to $\mathrm{C}-2 \mathrm{a}, \mathrm{C}-4, \mathrm{C}-5$ and $\mathrm{C}-6 \mathrm{a}$, from H-5 to C-3, C-4, C-6a and C-10, and from H-9 to C-4 in combination with the chemical shift gave proof for the 1,4-benzoxazine core structure of 1 . Further HMBC correlation from $\mathrm{H}-1^{\prime}$ to $\mathrm{C}-10, \mathrm{C}-2^{\prime}$ and $\mathrm{C}-3^{\prime}$, from $\mathrm{H}-2^{\prime}$ to $\mathrm{C}-1^{\prime}, \mathrm{C}-3^{\prime}$ and $\mathrm{C}-5^{\prime}$, from $\mathrm{H}-4^{\prime}$ to $\mathrm{C}-3^{\prime}$ and $\mathrm{C}-5^{\prime}$, and from $\mathrm{H}-6^{\prime}$ to $\mathrm{C}-5^{\prime}$ gave rise to an $\mathrm{N}$-acetylcysteine thioester attached to C-10 (Figure 4).

The X-ray crystal of 1 obtained from $\mathrm{CH}_{3} \mathrm{CN}$ gave further proof of the structure (Figure 5). To elucidate the absolute stereochemistry, $1 \mathrm{mg}$ of 1 was subjected to acid hydrolysis and subsequent amino acid analysis by chiral GC-MS. Comparison of the retention time

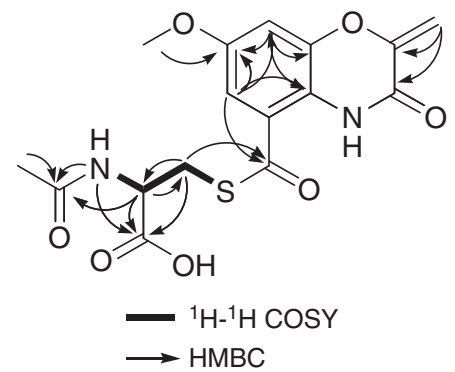

Figure $41 \mathrm{H}-1 \mathrm{H}$ COSY and HMBC correlations of benzoxacystol (1).

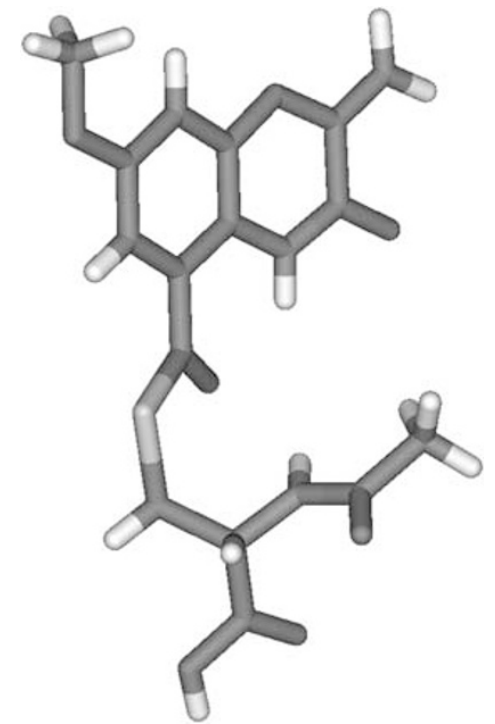

Figure 5 X-ray crystal structure of benzoxacystol (1). A full color version of this figure is available at The Journal of Antibiotics journal online.

$(\mathrm{Rt}=12.53 \mathrm{~min})$ to $\mathrm{D}$-cysteine $(\mathrm{Rt}=11.35 \mathrm{~min})$ and L-cysteine ( $\mathrm{Rt}=12.35 \mathrm{~min}$ ) showed the $R$ configuration of the stereogenic center in $\mathbf{1}$.

\section{Biological activity}

Compound $\mathbf{1}$ was tested for antimicrobial and antiproliferative activity by performing a variety of bioassays. It showed a weak antiproliferative activity against the mouse fibroblast cell line NIH$3 \mathrm{~T} 3$ at a concentration of $50 \mu \mathrm{M}$ (18\% inhibition). On the other hand, it was found to be inactive in the antimicrobial assays. Interestingly, compound 1 showed an inhibitory activity against glycogen synthase kinase $3 \beta$ (GSK-3 $\beta$ ) and inhibited the recombinant enzyme in an in vitro enzyme activity assay with an $\mathrm{IC}_{50}=1.35 \mu \mathrm{M} \pm 0.15 \mu \mathrm{M}$. GSK-3 $\beta$ is a key regulator of numerous signaling pathways and thus has emerged as a prominent target for the treatment of Alzheimer's disease and type 2 diabetes.

\section{DISCUSSION}

Strain NTK 935, a member of the Streptomyces griseus 16S rRNA gene clade, ${ }^{6}$ was isolated from a deep-sea sediment collected from the Canary Basin at the edge of the Saharan debris flow near the Canary Islands at a depth of $3,814 \mathrm{~m}$, using a piston corer. The age of the upper turbidite fraction ( 0 to $38 \mathrm{~cm}$ ) of the core, from which the strain was isolated, was deposited approximately 1000 years ago. ${ }^{9}$ It was 
shown that the number of actinobacteria-determined by operational taxonomic units (OTUs) based on 16S rRNA gene similiaritydecreased with the depth of the sediment core. ${ }^{10} 1406$ OTUs were determined in the core section 5 to $12 \mathrm{~cm}, 308$ OTUs in 15 to $18 \mathrm{~cm}$ and 212 OTUs in 43 to $46 \mathrm{~cm}$, respectively. However, only $9 \%$ of OTUs showed a 100-99\% homology in their 16S rDNA sequences with cultured actinobacteria, which demonstrated the huge diversity of unknown species in this unexploited habitat. This first study was corroborated by applying the multistage differential centrifugation technique (DDC) to the isolation of actinobacteria from marine sediments which resulted in an increased isolation of cultivable members of novel taxa. ${ }^{11}$

Recently we reported on caboxamycin, a new benzoxazole antibiotic from Streptomyces sp. NTK 937, which was isolated from the same sediment sample as strain NTK $935 .^{2}$ Both strains were screened by HPLC-diode array together with a further 36 streptomycete isolates from the Canary Basin sediment and resulted in the identification of known antibiotics, such as alteramide, antimycins, chromomycin, cyclothiazomycin, elaiophylin, lysolipin and sporaviridin. Besides strains NTK 935 and NTK 937, further strains were identified as producers of unknown metabolites, which are still under investigation and will be reported in forthcoming communications.

Benzoxacystol (1) represents a new 1,4-benzoxazine-type metabolite with an $\mathrm{N}$-acetylcysteine thioester. Only a limited number of 1,4-benzoxazine-type natural products are described in the literature. Benzoxazolinone was isolated from crushed rye plants and shown to be enzymatically transformed in the rye tissue from the 1,4-benzoxazin-3-one glycoside through its aglycone. ${ }^{12}$ Hydroxamic acids of 1,4-benzoxazin-3-one metabolites were found to exhibit an important role in defense mechanisms in cereal crops. ${ }^{13}$ The 1,4-benzoxazine chromophore was described as a building block of the antitumor enediyne antibiotic C-1027 produced by Streptomyces globisporus. ${ }^{7,8}$ Nevertheless, the majority of benzoxazine compounds described in the literature are of a synthetic nature, showing manifold biological activities, for example, histidine kinase inhibitors as potential antimicrobial agents. ${ }^{14}$ Inhibition of GSK-3 $\beta$, a key regulator of numerous signaling pathways, has not been reported from other benzoxazine compounds and benzoxacystol (1) is the first reported to exert this activity.

\section{METHODS}

\section{Producing organism and its classification}

Strain NTK 935 was isolated from an Atlantic Ocean deep-sea sediment core collected in 2001 at the southern edge of the Saharan debris flow near the Canary Islands $\left(27^{\circ} 02^{\prime} 392 \mathrm{~N}, 18^{\circ} 29^{\prime} 022 \mathrm{~W}\right)$, at a depth of $3814 \mathrm{~m}$. Isolations were made from the turbidite fraction of the core $(0-38 \mathrm{~cm}$ below the surface of the sediment), which was deposited approximately 1000 years ago. ${ }^{10}$

Strain NTK 935 was examined using a combination of genotypic and phenotypic procedures known to produce data of value in the delineation of Streptomyces species. ${ }^{15}$

Extraction of the DNA, amplification of the 16S rRNA gene sequence, as well as the sequencing procedure, were performed according to Wiese et al. ${ }^{16}$ The 16S rRNA sequence of strain NTK 935 was edited using BioEdit (http:// www.mbio.ncsu.edu/BioEdit/bioedit.html). The Ribosomal Database Project database (http://rdp.cme.msu.edu) was used to select the most clearly related type strains. ${ }^{17}$ Sequence similarity values were determined with the 'bl2seq' tool from the NCBI database (http://www.ncbi.nlm.nih.gov/Blast.cgi). ${ }^{18}$ The alignment of the 16S rRNA gene sequences of strain NTK 935, closest type strains, representatives of the genus Streptomyces and Micrococcus lylae as outgroup was perfomed with CLUSTAL X software and refined manually. ${ }^{19}$ All sequences were cut to the same length of $1417 \mathrm{bp}$. The phylogenetic tree was calculated with PhyML (http://atgc.lirmm.fr/phyml) by maximum likelihood analysis assuming the general time reversal model and applying 500 bootstrap replicates. ${ }^{20,21}$ NJplot (http://pbil.univ-lyon1.fr/software/njplot.html) was used to display the phylogenetic tree. ${ }^{22}$

\section{Biological activity}

Antimicrobial activity was tested against Bacillus subtilis DSM 347, Erwinia amylovora DSM 50901, Escherichia coli DSM 498, Pseudomonas fluorescens NCIMB 10586, Pseudomonas syringae DSM 50252, Ralstonia solanacearum DSM 9244, Staphylococcus lentus DSM 6672, Xanthomonas campestris DSM 2405 and Candida glabrata DSM 6425. The antimicrobial assays were performed as described by Helaly et al. ${ }^{23}$

To determine the cytotoxicity of compound 1, the sensitivity of the cell line NIH-3T3 was evaluated by monitoring the metabolic activity using the CellTiter-Blue ${ }^{-}$Cell Viability Assay (Promega, Mannheim, Germany). The cultivation of the cell line and the bioassay were performed as described by Schneemann et al. ${ }^{24}$

GSK-3 $\beta$ inhibition with compound 1 was determined in an in vitro assay adapted from a luminescent assay described by Baki et al. ${ }^{25}$

\section{Fermentation and isolation}

Batch fermentations of strain NTK 935 were carried out in a 10-1 stirred-tank fermentor (Biostat E; B.Braun, Melsungen, Germany) in a complex medium consisting of mannitol $20 \mathrm{~g}$ and soybean meal $20 \mathrm{~g}$ in 11 tap water; the $\mathrm{pH}$ was adjusted to 7.5 before sterilization. The fermentor was inoculated with $5 \%$ by volume of a shake flask culture grown in the same medium at $27^{\circ} \mathrm{C}$ in $500 \mathrm{ml}-$ Erlenmeyer flasks with a single baffle for $48 \mathrm{~h}$ on a rotary shaker at 120 r.p.m. The fermentation was carried out for 3 days with an aeration rate of 0.5 volume air per volume per minute and agitation at 250 r.p.m.

Hyphlo Super-cel (3\%) was added to the fermentation broth, which was separated by multiple sheet filtration into culture filtrate and mycelium. The culture filtrate was applied to an Amberlite XAD-16 column (Rohm and Haas; resin volume $800 \mathrm{ml}$ ) and the resin washed with $\mathrm{H}_{2} \mathrm{O}$ and $\mathrm{H}_{2} \mathrm{O}-\mathrm{MeOH}(1: 1)$. Compound 1 was eluted with $\mathrm{H}_{2} \mathrm{O}-\mathrm{MeOH}$ (25:75) and concentrated in vacuo to an aqueous residue. The concentrate was adjusted to $\mathrm{pH} 4.0$, extracted three times with EtOAc and the organic extracts combined and concentrated in vacuo to dryness. The crude product $(1 \mathrm{~g})$ was dissolved in $\mathrm{CH}_{2} \mathrm{Cl}_{2}$ and applied to a diol-modified silica gel column $(30 \times 2.5 \mathrm{~cm}$ i.d.; LiChroprep Diol, E. Merck, Darmstadt, Germany). Compound 1 was separated using a step gradient of $\mathrm{CH}_{2} \mathrm{Cl}_{2}-\mathrm{MeOH}$ and was eluted with $5 \% \mathrm{MeOH}$ at a flow rate $250 \mathrm{mlh}^{-1}$. Further purification was achieved by subsequent chromatography on Sephadex LH-20 (Amersham, Freiburg, Germany) and Toyopearl HW-40S (Tosoh Biosep, Stuttgart, Germany) with $\mathrm{MeOH}$ (each column $90 \times 2.5 \mathrm{~cm}$ i.d.) at a flow rate of $30 \mathrm{mlh}^{-1}$.

\section{HPLC-diode array analysis}

The chromatographic system consisted of an HP 1090M liquid chromatograph equipped with a diode-array detector and an HP Kayak XM 600 ChemStation (Agilent Technologies, Waldbronn, Germany). Multiple wavelength monitoring was performed at 210,230,260,280,310,360, 435 and $500 \mathrm{~nm}$, and UV-vis spectra measured from 200 to $600 \mathrm{~nm}$. A $10-\mathrm{ml}$ aliquot of the fermentation broth was centrifuged and the supernatant adjusted to $\mathrm{pH} 4$, and the preparation extracted with the same volume of EtOAc. After centrifugation, the organic layer was concentrated to dryness in vacuo and resuspended in $1 \mathrm{ml}$ $\mathrm{MeOH}$. Aliquots of $5 \mu \mathrm{l}$ of the samples were injected onto an HPLC column $(125 \times 3 \mathrm{~mm}$ i.d.), fitted with a guard-column $(20 \times 3 \mathrm{~mm}$ i.d. $)$ filled with 5- $\mu \mathrm{m}$ Nucleosil-100 C-18 (Maisch, Ammerbuch, Germany). The samples were analysed by linear gradient elution, using $0.1 \%$ ortho-phosphoric acid as solvent $\mathrm{A}$ and $\mathrm{CH}_{3} \mathrm{CN}$ as solvent $\mathrm{B}$ at a flow rate of $0.85 \mathrm{ml} \mathrm{min}^{-1}$. The gradient was from 4.5 to $100 \%$ for solvent B in 15 min with a 3-min hold at $100 \%$ for solvent $\mathrm{B}$.

\section{HPLC-ESI-MS analysis}

HPLC-ESI-MS analysis was done with an Agilent 1200 HPLC series equipped with a binary HPLC pump, autosampler, diode array detector, and a LC/MSD Ultra Trap System XCT 6330 (Agilent Technologies). Samples of $2.5 \mu$ l were injected onto an HPLC column (Nucleosil-100 C-18, $3 \mu \mathrm{m}, 100 \times 2 \mathrm{~mm}$ i.d.) 
and separated by $0.1 \%$ aqueous $\mathrm{HCOOH}$ as solvent $\mathrm{A}$ and $0.06 \% \mathrm{HCOOH}$ in $\mathrm{CH}_{3} \mathrm{CN}$ as solvent $\mathrm{B}$ by a linear gradient from $10 \% \mathrm{~B}$ to $100 \% \mathrm{~B}$ over $15 \mathrm{~min}$ at a flow rate of $400 \mu 1 \mathrm{~min}^{-1}$.

\section{Structure determination}

ESI-MS spectra were obtained on a QTRAP 2000 LC-MS/MS spectrometer (Applied Biosystems, Darmstadt, Germany). High-resolution HPLC-ESI-Orbitrap-FT mass spectra were recorded on an Orbitrap XL mass spectrometer (Thermo Scientific, Bremen, Germany) coupled to an Agilent 1200 HPLC system (Agilent Technologies), and NMR spectra were recorded on a DRX 500 spectrometer (Bruker, Karlsruhe, Germany) at 500 and $125 \mathrm{MHz}$ for ${ }^{1} \mathrm{H}$ and ${ }^{13} \mathrm{C}$, respectively. The chemical shifts are given in p.p.m. referred to dimethyl sulfoxide- $d_{6}$ as 2.50 p.p.m. $\left({ }^{1} \mathrm{H}\right)$ and $39.51\left({ }^{13} \mathrm{C}\right)$.

To analyze the absolute configuration of the amino acid moiety, 1 was first hydrolyzed with $6 \mathrm{M} \mathrm{HCl}$ at $110^{\circ} \mathrm{C}$ for $24 \mathrm{~h}$. The dry hydrolysate was subjected to ethanolic $\mathrm{HCl}$ at $110^{\circ} \mathrm{C}$ for $30 \mathrm{~min}$, followed by subsequent evaporation to dryness using a stream of nitrogen and then trifluoroacylated with trifluoroacetic anhydride in $\mathrm{CH}_{2} \mathrm{Cl}_{2}$ at $110^{\circ} \mathrm{C}$ for $10 \mathrm{~min}$. The reaction mixture was again evaporated to dryness, dissolved in toluene and analyzed by chiral GC-MS on Lipodex E/PS255 (30:70) capillary column $(20 \mathrm{~m} \times 0.25 \mathrm{~mm}$ i.d.).

X-ray diffraction data were collected on an Oxford Diffraction Xcalibur S diffractometer; the diffractometer was equipped with a Sapphire CCD detector and an enhanced monochromated MoK $\alpha$ source on a four-circle $\kappa$-platform (Agilent Technologies, Palo Alto, CA, USA). The diffraction frames were integrated by using the CrysAlisRed program, the set of data were corrected for empirical absorption with SCALE3 ABSPACK. ${ }^{26}$ The structure was solved by direct methods and refined using the program SHELX97. ${ }^{27}$ CCDC 807516 contains the supplementary crystallographic data for this paper. These data can be obtained free of charge from the Cambridge Crystallographic Data Centre via http://www. ccdc.cam.ac.uk/data_request/cif.

\section{ACKNOWLEDGEMENTS}

This work was supported by Boehringer-Ingelheim Pharma $\mathrm{GmbH}$ (Biberach, Germany) and the European Commission (project ACTINOGEN, 6th framework, grant LSHM-CT-2004-005224). We thank the crew of the RRS Charles Darwin for collecting deep-sea samples and Dr DG Masson (National Oceanography Centre, Southampton, UK) for access to the sediment cores and Mr A Kulik, Universität Tübingen for assistance in fermentations and HPLC-ESI-MS analyses.

1 Brötz, E. et al. Phenelfamycins $\mathrm{G}$ and $\mathrm{H}$, new elfamycin-type antibiotics produced by Streptomyces albospinus Acta 3619. J. Antibiot. 64, 257-266 (2011).

2 Hohmann, C. et al. Caboxamycin, a new antibiotic of the benzoxazole family produced by the deep-sea strain Streptomyces sp. NTK 937. J. Antibiot. 62, 99-104 (2009).

3 Fiedler, H. -P. Biosynthetic capacities of actinomycetes. 1. Screening for novel secondary metabolites by HPLC and UV-visible absorbance libraries. Nat. Prod. Lett. 2, 119-128 (1993).
4 Dictionary of Natural Products on DVD, Rev. 19:1 (CRC Press, London, UK, 2010).

5 Manfio, G. P., Zakrzewska-Czerwinska, J., Atalan, E. \& Goodfellow, M. Towards minimal standards for the description of Streptomyces species. Bioteckhnologia 8, 228-237 (1995).

6 Rong, X. \& Huang, Y. Taxonomic evaluation of the Streptomyces griseus clade using multilocus sequence analysis and DNA-DNA hybridization, with proposal to combine 29 species and 3 subspecies as genomic species. Int. J. Syst. Evol. Microbiol. 60, 696-703 (2010).

7 Sakawa, K. \& Yoshida, K. -I. Isolation and characterization of non-protein chromophore and its degradation product from antibiotic C-1027. J. Antibiot. 44, 564-568 (1991).

8 Liu, W., Christenson, S. D., Standage, S. \& Shen, B. Biosynthesis of the enediyne antitumor antibiotic C-1027. Science 297, 1170-1173 (2002).

9 Thomson, J. \& Weaver, P. P. E. An AMS radiocarbon method to determine the emplacement time of recent deep-sea turbidites. Sediment. Geol. 89, 1-7 (1994).

10 Stach, J. E. M. et al. Statistical approaches for estimating actinobacterial diversity in marine sediments. Appl. Environ. Microbiol. 69, 6189-6200 (2003).

11 Maldonado, L. A. et al. Diversity of cultivable actinobacteria in geographically widespread marine sediments. Antonie van Leeuwenhoek 87, 11-18 (2005)

12 Virtanen, A. I. \& Hietala, P. K. Precursors of benzoxazolidone in rye plants. I. Precursor II, the aglucone. Acta Chem. Scand. 14, 499-502 (1960).

13 Niemeyer, H. M. Hydroxamic acids (4-hydroxy-1,4-benzoxazin-3-ones), defence chemicals in the Gramineae. Phytochemistry 27, 3349-3358 (1988).

14 Mueller-Premru, M., Zidar, N., Spik, V. C., Krope, A. \& Kikely, D. Benzoxazine series of histidine kinase inhibitors as potential antimicrobial agents with activity against enterococci. Chemotherapy 55, 414-417 (2009).

15 Williams, S. T., Goodfellow, M. \& Alderson, G. Genus Streptomyces Waksman and Henrici 1943, 339AL. in Bergey's Manual of Systematic Bacteriology, Vol. 4 (ed. Williams, S. T. et al.) 2452-2492 (Williams \& Wilkins, Baltimore, USA, 1989).

16 Wiese, J., Thiel, V., Nagel, K., Staufenberger, T. \& Imhoff, J. F. Diversity of antibioticactive bacteria associated with the brown alga Laminaria saccharina from the Baltic Sea. Mar. Biotechnol. 11, 287-300 (2009).

17 Cole, J. R. et al. The ribosomal database project: improved alignments and new tools for rRNA analysis. Nucleic Acids Res 37, D141-D145 (Web Server Issue) (2009).

18 Tatsuova, T A \& Madden, T L. BLAST 2 sequences, a new tool for comparing protein and nucleotide sequences. FEMS Microbiol. Lett. 174, 247-250 (1999).

19 Larkin, M. A. et al. Clustal W and Clustal X version 2.0. Bioinformatics 23, 2947-2948 (2007).

20 Guindon, S. \& Gascuel, O. A simple, fast, and accurate algorithm to estimate large phylogenies by maximum likelihood. Syst. Biol. 52, 696-704 (2003).

21 Keane, T. M., Creevey, C. J., Pentony, M. M., Naughton, T. J. \& McInerney, J. 0. Assessment of methods for amino acid matrix selection and their use on empirical data shows that ad hoc assumptions for choice of matrix are not justified. BMC Evol. Biol. 6, 29 (2006).

22 Perrière, G. \& Goug, M. WWW-Query: an on-line retrieval system for biological sequence banks. Biochemie 78, 364-369 (1996).

23 Helaly, S. et al Gombapyrones, new $\alpha$-pyrone metabolites produced by Streptomyces griseoruber Acta 3662. J. Antibiot. 62, 445-452 (2009).

24 Schneemann, I. et al. Mayamycin, a cytotoxic polyketide from a Streptomyces strain isolated from the marine sponge Halichondria panicea. J. Nat. Prod. 73, 1309-1312 (2010).

25 Baki, A., Bielik, A., Molnar, L., Szendrei, G. \& Keseru, G. M. A. High throughput luminescent assay for glycogen synthase kinase-3 $\beta$ inhibitors. Assay Drug Dev. Technol. 5, 75-83 (2007).

26 SCALE3 and CrysAlisRed, Version 1.171.29.10 (Oxford Diffraction Ltd. Abingdon, Oxford, UK, 2006).

27 Sheldrick, G. M. SHELX97, Program Package for the Solution and Refinement of Crystal Structures, Release 97-2 (University of Göttingen, Germany, 1997). 